Original Research

\title{
The Effectiveness of Prone and Supine Nesting Positions on Changes of Oxygen Saturation and Weight in Premature Babies
}

\section{Ayu Prawesti, Etika Emaliyawati, Ristina Mirwanti and Aan Nuraeni}

Faculty of Nursing, Universitas Padjadjaran, Bandung, Indonesia

\begin{abstract}
Introduction: Stress experienced by the baby will affect the body's function by increasing the body's metabolism. Nesting is used to reduce stress in premature babies. Nesting can be done in a supine or prone position. Few studies have examined the effects of body position on body weight and oxygen saturation. The objective of the study was to determine the difference in oxygen saturation and weight change on the use of nesting in the prone and supine positions in premature babies.
\end{abstract}

Methods: The research used a quasi-experimental design. The sample consisted of 30 premature babies, which was obtained using a consecutive sample technique. The independent variables were nesting positioning (supine and prone), and the dependent variables were oxygen saturation and body weight. The data of oxygen saturation and the baby's weight were collected using pulse oximetry; the baby's weight scale used observation sheets. The data was analysed using the t-test, Wilcoxon Sign Ranks Test, and Mann Whitney U Test.

Results: The results showed that there was a difference in oxygen saturation before and after the use of nesting in the supine $(p=0.001)$ and prone position $(p=0.000)$. There was a weight difference before and after the use of nesting in both supine $(p=0.000)$ and prone position $(p=0.000)$. There was no difference in oxygen saturation value and infant weight, before or after, between the supine position and the prone position $(\mathrm{p}=0.18 ; \mathrm{p}=0.9)$.

Conclusion: The use of nesting in both positions (supine or prone) can increase oxygen saturation and infant weight. Researchers recommend the use of nesting with supine or prone positions routinely in premature babies.

\section{ARTICLE HISTORY}

Received: Feb 26, 2018

Accepted: Dec 12, 2019

\section{KEYWORDS}

nesting; oxygen saturation; premature babies; weight

\section{CONTACT}

Ayu Prawesti

$\triangle$ ayu.prawesti@unpad.ac.id $\equiv$ Emergency and Critical Care Nursing Departement, Faculty of Nursing, Universitas Padjadjaran, Bandung, Indonesia

Cite this as: Prawesti, A., Emaliyawati, E., Mirwanti, R., \& Nuraeni, A. (2019). The Effectiveness of Prone and Supine Nesting Positions on Changes of Oxygen Saturation and Weight in Premature Babies. Jurnal Ners, 14(2), 138144. doi:http://dx.doi.org/10.20473/jn.v14i2.7755

\section{INTRODUCTION}

The process of environment adjustment for premature babies is going to be more difficult. This difficulty of adjustment is due to immaturity of the organ system (Sari, 2018). Immunity of organs in premature babies includes immaturity of the nervous system and low stability in the physiological functions of the infant, low ability to solve stress in the infant will affect the body's function, and will affect the function of the hypothalamus, which will adversely affect growth, heat production and neurological mechanisms (Hockenberry \& Wilson, 2013). Stress in the baby will affect the function of the body by increasing its metabolism, so it requires more oxygen consumption to stabilize physiological functions.
The WHO stated that $44 \%$ of infant deaths in the world in 2012 occurred within the first 28 days, and the major cause was premature birth, accounting for approximately 37\% (WHO, 2012). In Indonesia, based on data from the Health Profile of Indonesia in 2014, it states that the highest incidence of deaths in babies occurred during the neonatal stage. Basic Health Research (Ministry of Health of the Republic of Indonesia, 2018) showed that $78.5 \%$ of deaths occurred in neonates at 0-6 days).

Increased oxygen consumption will cause a risk of respiratory distress, acidosis and hypoxia (Hockenberry \& Wilson, 2013). Physiological changes in increasing stress hormones increase pulse rate and decrease oxygen saturation (Oken, Chamine, \& Wakeland, 2015). Another impact of stress 
experienced by premature babies can lead to excessive use of energy, causing barriers to energy conservation resulting in weight gain difficulties (Hockenberry \&Wilson 2013). Low-weight babies will have a much heavier adaptation than high-weight babies (Bayuningsih, 2011).

One effort in the provision of developmental care is to set a comfortable position on the neonate using nesting. Nesting is a material made of phlanyl fabric with the length adjusted to the baby's body length which acts as a protective position for the baby so that it is not in an extension condition, and also keeps the baby's position changing as a result of gravity (Kahraman, Başbakkal, Yalaz, \& Sözmen, 2018). The benefit of using nesting in neonates is to facilitate hand to hand and hand to mouth position patterns so that the flexion position is maintained (Priya \& Biljani, 2005).

Another study on the benefits of nesting explains that nesting is effective in improving comfort and hemodynamic stability in weight babies in the Neonatal Intensive Care Unit (NICU) (Anju \& Paulose, 2015). The use of nesting in premature babies is done in the prone or supine position. Bayuningsih, Rustina, \& Widyatuti (2011) conducted a study of the effectiveness of nesting and prone position against oxygen saturation and pulse frequency in premature babies. It was found that there was a significant difference in oxygen saturation in infants using nesting in the prone position. Based on studies in the perinatology room of one of the referral hospitals in Bandung, where nesting is used with supine position, the baby looks more comfortable, sleeps longer and allows the nurse to observe it. Based on a previous study on 6 infants with 3 infants using the prone position while in nesting, and 3 infants positioned in supine flexion. It was found that oxygen saturation was increased in all infants, but increases were found in oxygen saturation in 2 infants in the prone position, which is lower than the others because the two infants look uncomfortable and always moved; after their position was changed in the supine, they did not move much, and oxygen saturation increased. From the results of previous study and existing phenomena in the room, researchers were interested in examining whether using nesting and the supine baby position influences oxygen saturation and infant weight in response to physiological stability. Thus, the objective of this study was to identify oxygen saturation and body weight in premature babies before and after using nesting in the supine and prone positions.

\section{MATERIALS AND METHODS}

The design of this study used a quasi-experimental design. The population in this study were premature babies treated in the perinatology ward in one of the referral hospitals in West Java Province, and the average number of babies undergoing treatment each month was 40 babies. The research sample used a consecutive sampling technique. The sample inclusion criteria were premature babies weighing 1500-2000 grams, premature babies get nutrition through sonde, premature babies are treated in incubators and the baby's parents allowed the baby to be the subject of the research. Sample exclusion criteria are premature babies with NEC (necrotic enterocolitis), anemia, sepsis and hyperbilirubinemia, premature babies with lung problems and respiratory function and premature babies with congenital abnormalities. Drop out criteria is premature babies who died during ongoing research. Based on inclusion and exclusion criteria, 15 infants were in the supine position and the other 15 infants were in the prone position.

The instruments used in this study include an observation sheet, pulse oximetry and a baby weight scale. The observation sheet contains patient data consisting of name, gender, gestation, age. Further data are vital signs such as temperature, type of nutrition, oxygen saturation and weight. Pulse oximetry was used to measure oxygen saturation and used a new pulse oximetry, with a blue brand fingertip pulse oximeter - pulse rate and $\mathrm{SpO} 2$ monitor, which was calibrated at the time of removal by the manufacturer. The baby weight scale was used to measure the baby's weight, that is in Perinatology room that was scale calibrated on 28 March 2016.

Before data collection, the researcher gained informed consent from the parents of premature babies; all the parents had been informed and signed the consent form. Data retrieval began by determining the respondent according to the criteria. Oxygen saturation and weight gain had been recorded before using nesting in the supine and prone positions and then documenting them on observation sheets. The nesting position is the position where premature babies are placed in a circle, similar to a position taken when in the womb with two hands in front of the chest, with the chin touching the chest. With this same position the baby in nesting can be placed in a supine or prone position.

In the final stage, data for oxygen saturation were collected before the premature babies slept in the nesting position (pre-test) and then they were positioned nesting supine (for group supine) and prone (for prone group) for 20 minutes. Their saturation were measured, after which they were positioned into the nesting prone position and supine position (post-test nesting supine and prone). This intervention was only held once a day for 7 days. After 7 days the baby slept in the nesting position, baby weight was weighed and the result of the assessment was written on the observation sheet. Data analysis used in this research is univariate analysis, normality test, and bivariate analysis. Univariate analysis explains and describes characteristics of variables to be studied, that is oxygen saturation frequency distribution before and after using nesting and distribution of frequency of body weight before and after using nesting. 
Table 1. Characteristic Demographic $(n=30)$

\begin{tabular}{|c|c|c|c|c|}
\hline \multirow{2}{*}{ Characteristics } & \multicolumn{2}{|c|}{ Supine } & \multicolumn{2}{|c|}{ Prone } \\
\hline & $\mathbf{n}$ & $\%$ & $\mathbf{n}$ & $\%$ \\
\hline \multicolumn{5}{|l|}{ Sex } \\
\hline Male & 4 & 26.67 & 10 & 66.67 \\
\hline Female & 11 & 73.33 & 5 & 33.33 \\
\hline \multicolumn{5}{|l|}{ Gestational Age } \\
\hline 32 Weeks & 4 & 26.67 & 3 & 20 \\
\hline 33 Weeks & 6 & 40 & 4 & 26.67 \\
\hline 34 Weeks & 5 & 33.33 & 8 & 53.33 \\
\hline \multicolumn{5}{|l|}{ Body temperature } \\
\hline $36.5^{\circ} \mathrm{C}$ & 4 & 26.67 & 1 & 6.67 \\
\hline $36.6^{\circ} \mathrm{C}$ & 3 & 20 & 3 & 20 \\
\hline $36.7^{\circ} \mathrm{C}$ & 4 & 26.67 & 4 & 26.67 \\
\hline $36.8^{\circ} \mathrm{C}$ & 3 & 20 & 6 & 40 \\
\hline $36.9^{\circ} \mathrm{C}$ & 1 & 6.66 & 1 & 6.66 \\
\hline \multicolumn{5}{|l|}{ Food supply } \\
\hline Breast milk + Formula Milk & 15 & 100 & 15 & 100 \\
\hline
\end{tabular}

The data normality test used Shapiro Wilk. Bivariate analysis was conducted to see the effect of nesting (supine and prone) toward oxygen saturation and body weight in premature babies in the perinatology room. Prone position data including oxygen saturation and weight had normal data distribution and they were tested by a paired t-test, and supine position data had abnormal data distribution, so the test was conducted using Wilcoxon difference test. To see the differences of oxygen saturation value change and body weight between using nesting at prone position and supine position they were tested using the Mann Whitney test. Then the results of the analysis were interpreted by using significance test $\alpha=0.05$ and confidence interval (CI) 95\%.

Ethical clearance for data collection had been obtained from the research ethics committee of the General Hospital No. LB.02.01/C02/1329/1/2017. All respondents had been informed consent and agreed to participate in the research.

\section{RESULTS}

Based on the table 1, it can be explained that the respondents in supine groups were mostly female, as many as 11 premature babies (73.3\%) with 33 weeks' gestation age of 6 premature babies ( $40 \%)$. However, the respondents in prone groups were mostly male, as many as 10 premature babies (66.67\%) with 34 weeks' gestation age of 8 premature babies (53.33 $\%)$. All the respondent's body temperatures were within the normal body temperature range, which is between $36.5 \mathrm{o}-36.9 \mathrm{oC}$ and for the type of food given to infants as a whole (100\%), respondents were given a similar type of food, namely breast milk and formula milk.

Table 2 showed that oxygen saturation of infants after 20 minutes using nesting in supine and prone positions increased oxygen saturation. In the supine position, the minimum oxygen saturation after intervention was $93 \%$, and in some of the infants the saturation could increase up to $98 \%$. Furthermore, there is a difference in oxygen saturation before and after using nesting in the supine position $(\mathrm{p}=0.001<$ $0.005)$. Otherwise, after a prone position, the infants' oxygen saturation was in the range of $95 \%$ to $98 \%$, and there is a difference in oxygen saturation before and after using nesting in the prone position $(\mathrm{p}=$ $0.000<0.005$ ). Based on the Mann Whitney test, there is no difference in oxygen difference between the supine and prone positions ( $\mathrm{p}=0.180>0.005)$.

Based on table 2, it can be seen that after seven days using nesting in the supine and prone position, the baby's increased their weight. The amount of babies who reached their weight of more than 2000 grams was increased. There are differences in body weight before and after using nesting both in the position of supine $(\mathrm{p}=0.000<0.005)$ and prone position $(\mathrm{p}=0.000<0.005)$, but there was no difference in weight gain in the supine and prone positions $(p=0.900>0.005)$

\section{DISCUSSION}

\section{Effect of nesting on oxygen saturation}

Based on Table 2 the results showed that the baby's oxygen saturation after 20 minutes using nesting in supine and prone positions increased oxygen saturation. The results of this study are reinforced by the results of different test analyses, considering the change in oxygen saturation value after using nesting. According to Table 2 there is no decrease in oxygen saturation between before and after using nesting in the supine position. In 15 respondents there was an increase in oxygen saturation before and after using nesting in the supine position. As can be seen on Rank Ties, which is 0 , so there is no equal oxygen saturation value between before and after using nesting in the supine position. Furthermore, the value of $p$-value, which is 0.001 , then $p$-value <alpha value $(0.05)$ shows that there is difference in oxygen saturation before and after using nesting in the supine position.

In the supine position, increases in oxygen saturation are due to the supine position having 
Table 2. Oxygen Saturation and weigh Before and After Using Nesting in supine and prone position ( $\mathrm{n}=30$ )

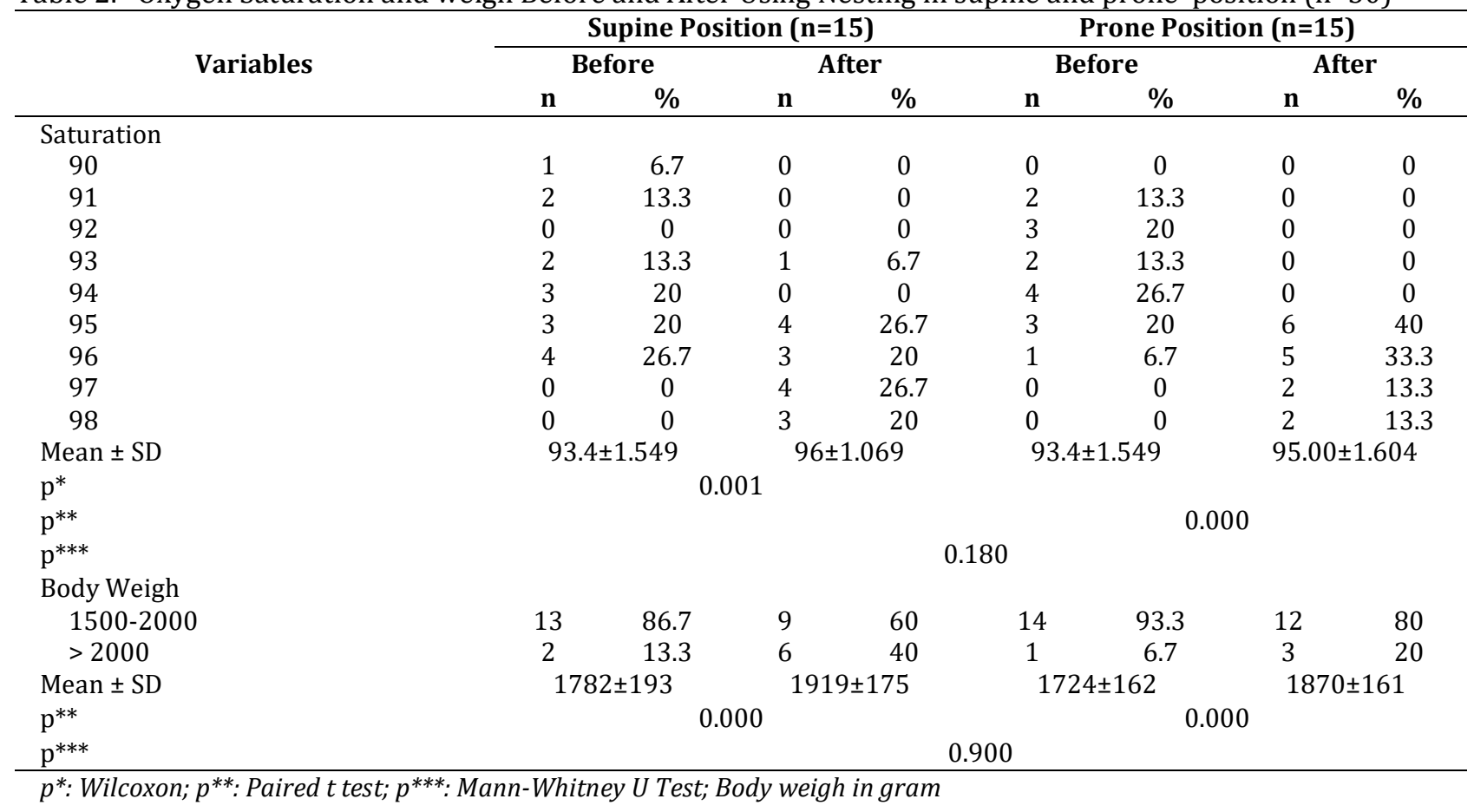

better respiratory muscle strength and low episodes of hyposexuality. This occurs mainly in the supine position with a 45 degree head elevation, where the development of the lungs becomes maximal (Spooner et al., 2014). The use of nesting in the supine position may affect the increase in oxygen saturation value in premature babies because using nesting can adjust the infant in a flexible position. The flexible position can serve as a safety measure to prevent heat loss caused by body surfaces exposed to room temperature. Heat loss in premature or hypotermic infants will require many calories for the stability of body temperature, so it will cause increasing oxygen consumption, and nesting ensures the flexible position, so the metabolic rate will be decreased, the oxygen in the body is enough, so the saturation rate will be increased. The flexible position in premature babies is a good position because it will affect relaxation and reduce metabolism (Kahraman et al. 2018).

The use of nesting in prone positions in Table 2 indicates that there is a difference in oxygen saturation before and after using nesting. This is proven by a higher mean value in oxygen saturation after using nesting and p-value $(0.000)<$ alpha value (0.05), indicates that there is an influence of using nesting in prone position to oxygen saturation value. The results of this research are in line with another study (Bayuningsih et al., 2011), that using nesting affects the increase of oxygen saturation by $\mathrm{p}$ value = 0.001. In the study (Bayuningsih et al., 2011) the baby position in nesting is prone. The prone position can reduce pressure on the diagfragma, decrease the apneu period and reduce the esophageal reflex, so it can increase lung volume capacity (Abdeyazdan, Nematollahi, Ghazavi, \& Mohhamadizadeh, 2010).
Based on the results of the study, it showed that the use of nesting in supine and prone positions influences the change of oxygen saturation value. This research conducted a different test to the oxygen saturation value change between nesting in prone position and nesting in supine position. This is conducted to find out the best position to get a better oxygen saturation value. Based on table 7 it is found that there is no difference in the difference value of oxygen saturation change in the supine and prone positions, it is proven by $\mathrm{p}$-value $>$ alpha (0.05).

The results of this study contrast with (Abdeyazdan et al., 2010)'s research that the prone position obtained oxygen saturation value is higher than in the supine position (Abdeyazdan et al., 2010). In a study conducted by Abdeyazdan, oxygen saturation measurement was performed for 120 minutes of using nesting, while in this research it is only measured oxygen saturation after nesting for just 20 minutes. The inhabitant factor of nesting can affect the increase in oxygen saturation. Several studies have shown that there is an increase in the oxygen saturation value during the use of nesting in the prone position of about 1.18 to $4.36 \%$ (RivasFernandez, Roqué i Figuls, Diez-Izquierdo, Escribano, \& Balaguer, 2016)

Based on the results of the research, it showed that the use of nesting in infants has an effect on increases in the oxygen saturation value. Differences in supine or prone positions in using nesting do not differ in effect on increasing oxygen saturation, since both cause an increase in oxygen saturation value in nesting usage. Nesting is a barrier that serves to support the baby's body. Nesting can reduce acute stress in infants due to sudden and surprising movements (Borle, 2015). Another study proves that nesting can reduce stress in premature babies. 
Nesting can reduce stress and pain levels in premature babies compared to non-nesting infants at the time of diaper replacement (Comaru \& Miura, 2009). The use of nesting has a positive impact on reducing stress in premature babies, because stress in premature babies can activate the stress hormone which will further affect the increase in pulse rate and decrease oxygen saturation (Maguire et al., 2009).

Factors of oxygen saturation according to (Brooker Chris, 2009) are body temperature, hemoglobin, hyperbilirubin and hypoxemia. Body temperature can affect oxygen saturation because if there is an increase or decrease in body temperature this will increase metabolism. Increased metabolism requires more oxygen levels and will cause a decrease in oxygen saturation. In this research preterm babies, as the sample of the research, had a normal body temperature, which is 36.5-36.8, it will not affect the results of this research. Another factor that affects oxygen saturation is anemia. Anemia is decreasing of hemoglobin, so it will decrease oxygen levels that bind to $\mathrm{Hb}$ and will decrease the oxygen saturation value. In addition, hyperbilirubin and hypoxemia will affect oxygen saturation, but in this study the three factors did not affect the results of the study because infants with anemia, hyperbilirubin and hypoxemia were included in the exclusion criteria.

Oxygen saturation levels in infants are very important to be known because when the oxygen saturation level in infants is low, there is a risk of hemodynamic abnormalities. Normal values of oxygen saturation range from $95 \%$ to $100 \%$, at $28-34$ weeks of normal oxygen saturation value $88 \%$ to $94 \%$ and in infants with gestational age, $<28$ weeks, the normal value of oxygen saturation $85 \%$ to $92 \%$ is still considered normal (Snoek et al, 2016).

\section{Effect of nesting on oxygen saturation}

Table 2 shows that after 7 days of using nesting in supine and prone positions weight was gained. The results of this research are reinforced by the results of different test analyses by considering changes in infant weight after using nesting in supine and prone positions. Based on table 2, it can be concluded that there are differences in body weight before and after using nesting both in prone and supine positions, evidenced by the value of p-value $(0.000)<$ value alpha (0.05), but the difference in average infant weight gain before and after using nesting is greater in preterm infants positioned in the prone rather than the supine position.

The research also compared differences in changes in infant weight gain between using nesting in the supine and prone positions. This is done to find a better position to increase the weight of premature babies. The comparison of the difference in oxygen saturation value difference between the two positions (supine and prone) was explained in table 2., it is found that there is no difference in the difference value of change and there is no difference of weight in supine and prone position, it is proved by $\mathrm{p}$-value> alpha (0.05).

Based on the results above, it can be concluded that the use of nesting in supine position and prone positions affect weight gain. Different positions during the use of nesting for infant weight gain show no significant difference in outcome, so nesting can be used in either the supine or prone position. Nesting facilitates the baby in a flexible position that protects the baby from increased metabolism due to stimuli from the environment that can lead to stress and improve the quality of the baby's sleep, so there is no excessive use of energy. Energy that is not used by the body will be stored in the adipose system and increases body weight (Reyhani, Ramezani, Boskabadi, 2016).

Nesting can increase infant growth. It is known from several studies including research of (Kahramen et al., 2017) that improving the quality of sleep will reduce energy consumption or resting energy expenditure (REE). Decreasing REE will improve efficiency and metabolism, thereby increasing the weight of premature babies. Nesting will increase growth because the use of nesting can facilitate the baby to have a longer deep sleep period (Prasanna \& Radhika, 2015). In a deep sleep state, $75 \%$ of the growth hormone is produced. This is in line with (Reyhani, Ramezani, Boskabadi, \& Mazlom, 2016) study that deep sleep in premature babies reduces the crying period which can lead to excessive energy consumption, so no extra energy can be stored, finally it can lead to weight loss (Reyhani, Ramezani, Boskabadi, 2016).

Human growth hormone is an anabolic hormone that plays a very big role in the growth and formation of the body, especially in childhood and puberty. Growth hormone (GH) plays a role in increasing the size and volume of brain, hair, muscles and organs in the body. GH is responsible for human growth from birth. The growth secretion of growth hormone is physiologically regulated by the hypothalamus. The hypothalamus produces Growth Hormone Releasing Factor (GHRF) which stimulates the secretion of growth hormones. The secretion is increased in the state of deep sleep (Kim et al 2015).

According to (Indriansari, 2011) using a quasiexperimental method with a sample of 15 low birth weight babies results in an increase in sleep duration in infants using nesting compared to infants in the control group. Achieving deep sleep is very important in infants as it facilitates low birth weight infants to grow and develop optimally (Rahmawaty, 2016)

Deep sleep is essential for energy conservation, decreased peripheral muscle tone and arterial blood pressure, decreased pulse rate, and resting muscles during deep sleep. Infants who fall asleep in nesting as an indicator of decreased stress due to stress reduction will elicit a relaxed response induced by muscle relaxation and sleep. The sleep phase is a very important phase for the baby because during this phase the secretion of growth hormone and body immunity occurs (Irwin, 2015) . 
In general, in this research the weight of respondents experienced an increase after using nesting. The median weight of infants before using nesting was 1753.5 grams and after using nesting was 1894 grams, the weight of premature babies rose in 140.5 grams for 7 days, this is in line with (Mohrbacher, N. \& Stock, 2010) that the baby's weight gain will increase by 15-20 grams/day in early life. This happens either in term infants or in premature babies.

Body weight is the result of increasing or decreasing all existing system in the body and a parameter can provide a picture of body mass. Body mass is very sensitive to sudden changes, such as infectious diseases, decreased amount of food consumed and increased metabolism (Drassinower, Friedman, Običan, Levin, \& Gyamfi-Bannerman, 2016). Factors that affect weight gain are nutrients because the fulfilment of nutritional and fluid needs in premature babies in the room are adjusted for weight and gestational age. Fulfil the needs of infants by $60-80 \mathrm{cc} / \mathrm{kg} \mathrm{BW} /$ day which gradually increases up to $100-200 \mathrm{c} / \mathrm{kg} \mathrm{BW} /$ day after the first week. The initial fluid given early in the baby's life is breast milk. If no breast milk is given, then pregestimil with $2 \mathrm{x}$ dilution is provided. Premature babies have only a small amount of energy reserves because of the lack of glycogen reserves under the skin. The need for premature babies is divided into 2 important components that need to be maintained for body functions and the need to grow (Johnson \& Marlow, 2017). All respondents in this research obtained a combined nutrition between breast milk and formula milk. Nutrition obtained by all respondents is the same, so the nutritional factors have no effect on the results of the study.

\section{LIMITATION}

This study has limitations, the number of respondents in this study was small, besides saturation measurements were only performed once for saturation oxygen, even though the intervention was carried out for seven days.

\section{CONCLUSION}

Nesting in a supine position and in a prone position affects oxygen saturation and weight gain. This is proven by the difference in oxygen saturation and weight gain that increases before and after using nesting. Differences in the position of infants during the use of nesting did not affect the difference in the increase in oxygen saturation values and body weight. Furthermore, it is recommended that nesting in supine and prone positions can be chosen as one of the interventions to care for premature babies in improving oxygen saturation and weight. The results of this study can be used as a reference for the manufacture of standard operating procedures in the NICU ward because the process involves nurses, doctors, families and other officers, so it can run well. Future researchers should conduct research in more samples and with a longer observation time $(120$ minutes) using the control group of supine and prone positions on the use of nesting, so the results will be more significant.

\section{REFERENCES}

Abdeyazdan, Z., Nematollahi, M., Ghazavi, Z., \& Mohhamadizadeh, M. (2010). The effects of supine and prone positions on oxygenation in premature infants undergoing mechanical ventilation. Iranian Journal of Nursing and Midwifery Research, 15(4), $229-233$.

Anju, T. R., \& Paulose, C. S. (2015). Long term effects of neonatal hypoglycaemia on pancreatic function. Archives of Physiology and Biochemistry, 121(1), 112. https://doi.org/10.3109/13813455.2014.96087 4

Bayuningsih, R. (2011). Efektifitas Penggunaan Nesting Dan Posisi Prone Terhadap Saturasi Oksigen Dan Frekuensi Nadi Pada Bayi Prematur Di Rumah Sakit Umum Daerah Bekasi.

Bayuningsih, R., Rustina, Y., \& Widyatuti. (2011). Efektivitas Penggunaan Nesting Dan Posisi Prone Terhadap Saturasi Oksigen Dan Frekuensi Nadi Pada Bayi Prematur Di Rumah Sakit Umum Daerah (RSUD) Kota Bekasi. Jurnal FIK UI.

Borle, P. S. (2015). Effectiveness of Nesting on Posture and Movement of Upper Extremities in Healthy Preterm Infants, (July), 143-146.

Brooker Chris. (2009). Churchill livingstone's mini encyclopedia of nursing. (B. Chris, Ed.). Jakarta: EGC.

Comaru, T., \& Miura, E. (2009). Postural support improves distress and pain during diaper change in preterm infants. Journal of Perinatology, 29(7), 504-507. https://doi.org/10.1038/jp.2009.13

Deprtemen Kesehatan Republik Indonesia. (2013). Riset Kesehatan Dasar. Jakarta. https://doi.org/1 Desember 2013

Dimitriou, G., Greenough, A., Pink, L., McGhee, A., Hickey, A., \& Rafferty, G. F. (2002). Effect of posture on oxygenation and respiratory muscle strength in convalescent infants. Arch Dis Child Fetal Neonatal Ed, 86(3), F147-50. https://doi.org/10.1136/FN.86.3.F147

Drassinower, D., Friedman, A. M., Običan, S. G., Levin, H., \& Gyamfi-Bannerman, C. (2016). Prolonged latency of preterm premature rupture of membranes and risk of neonatal sepsis. American Journal of Obstetrics and Gynecology, 214(6), 743e1. https://doi.org/10.1016/j.ajog.2015.12.031

Hockenberry, M. J., \& Wilson, D. (2013). Wong's Essentials of Pediatric Nursing. Elsevier Health Sciences.

Indriansari, A. (2011). pengaruh developmental care terhadap fungsi fisiologis dan perilaku tidur terjaga bayi berat lahir rendah di RSUP Fatmawati Jakarta. FIK UI.

Irwin, M. R. (2015). Why sleep is important for health: a psychoneuroimmunology perspective. Annual 
Review of Psychology, 66, 143-172. https://dx.doi.org/10.1146\%2Fannurev-psych010213-115205

Johnson, S., \& Marlow, N. (2017). Early and long-term outcome of infants born extremely preterm. Archives of Disease in Childhood, 102(1), 97-102. https://doi.org/10.1136/archdischild-2015309581

Kahraman, A., Başbakkal, Z., Yalaz, M., \& Sözmen, E. Y. (2018). The effect of nesting positions on pain, stress and comfort during heel lance in premature infants. Pediatrics \& Neonatology, 59(4), 352-359. https://doi.org/10.1016/j.pedneo.2017.11.010

Lubetzky, R., Mimouni, F. B., Dollberg, S., Reifen, R., Ashbel, G., \& Mandel, D. (2010). Effect of Music by Mozart on Energy Expenditure in Growing Preterm Infants. Pediatrics, 125(1), e24-e28. https://doi.org/10.1542/peds.2009-0990

Maguire, C. M., Walther, F. J., Sprij, A. J., Le Cessie, S., Wit, J. M., \& Veen, S. (2009). Effects of Individualized Developmental Care in a Randomized Trial of Preterm Infants \&lt;32 Weeks. Pediatrics, 124(4), 1021-1030. https://doi.org/10.1542/peds.2008-1881

Ministry of Health of the Republic of Indonesia. (2018). Hasil Riset Kesehatan Dasar 2018 [Basic Health Research Results]. Jakarta.

Mohrbacher, N. \& Stock, J. (2010). Breast feeding answer made simple a guide for helping mother. Scaunbur, Illinois: L $:$ a Leche League International.

Moller, H. J. (Ed.). (2012). Pediatric Cardiovascular Medicine, 2nd Edition. Wiley-Blackwell.

Nair, M. N. G., \& Raghuraman, T. S. (2004). NICU environment. Can we be ignorant? (multiple letters) [4]. Medical Journal Armed Forces India, 60(1), 97. https://doi.org/10.1016/S03771237(03)80046-1

Oken, B. S., Chamine, I., \& Wakeland, W. (2015). A systems approach to stress, stressors and resilience in humans. Behavioural Brain Research, 282, 144-154. https://doi.org/10.1016/j.bbr.2014.12.047

Prasanna, M. K., \& Radhika, M. (2015). Effectiveness of Nesting on Posture and Motor Performance Among, (2277), 4-7.

Priya, G. S. K., \& Biljani, J. (2005). Low cost positioning device for nesting preterm and low birth weight neonates. Pratical on Call Child Health Care, 5(3), 54-59.

Rahmawaty. (2016). Pengaruh nesting terhadap saturasi oksigen dan berat badan pada bayi prematur di ruang perinatologi RUP Dr Hasan Sadikin. UNPAD.

Reyhani, Ramezani, Boskabadi, M. (2016). Evaluation of the Effect of Nest Posture on the Sleep Wake State of Premature Infants, 6, 29-36.

Reyhani, T., Ramezani, S., Boskabadi, H., \& Mazlom, S. (2016). Evaluation of the effect of nest posture on the sleep-wake state of premature infants. Evidence Based Care, 6(1), 29-36.

Rivas-Fernandez, M., Roqué i Figuls, M., DiezIzquierdo, A., Escribano, J., \& Balaguer, A. (2016). Infant position in neonates receiving mechanical ventilation. Cochrane Database of Systematic Reviews. https://doi.org/10.1002/14651858.CD003668.p ub4

Saifuddin, A. (2001). Buku Acuan Nasional Pelayanan Kesehatan Maternal dan Neonatal. Jakarta: Yayasan Bina pustaka Sarwono Prawirohardjo.

Sari, W. . (2018). Effect Of Implementation of Developmental Care: Nesting On Sleep And Physiological Parameters Baby Premature In Hospital X Bandung. In International Conference on Heath Care and Management. Bandung.

WHO. (2012). Born too soon. 